\title{
The ownership and protection of multinational inventions - in particular inventions resulting from publicly funded research
}

\author{
Statement prepared by the ALLEA Permanent Working Group Intellectual Property Rights*
}

\begin{abstract}
* Members of the ALLEA Permanent Working Group Intellectual Property Rights: Joseph Straus (Chair), Delegate of the Union of the German Academies of Sciences and Humanities; Yuriy Kapitsa, National Academy of Sciences of Ukraine (Lead author); Are Stenvik (Co-author), Norwegian Academy of Arts and Sciences; William Cornish, British Academy; Carlo D’Adda (ex officio, ALLEA Board Member), Accademia Nazionale dei Lincei, Italy; P. Bernt Hugenholtz, Royal Netherlands Academy of Sciences and Humanities; Paul O'Brien, Royal Society, United Kingdom; Alain Strowel, Universite Catholique de Louvain, Saint-Louis University, Belgium; Ünal Tekinalp, Bilim Akademisi (Science Academy), Turkey; Tomasz Twardowski, Polish Academy of Sciences; Sylvester Vizi, Hungarian Academy of Sciences
\end{abstract}

The increase of international cooperation in research and development is resulting in more inventions being the outcome of such cooperation. The EU is supportive of these developments and has set up rules to administer this internationalisation. However, neither Regulation (EU) 1290/2013nor any other legislative measure provides for harmonisation with national law on inventorship, assignment, and patent filing requirements for multinational inventions. This legal complexity hampers efficiency and leads to legal uncertainty with respect to the choice of law(s) governing inventorship. As it stands, ALLEA observes the lack of harmonisation and invites the European Commission to 1) analyse the effect of diverging national rules on inventorship, assignment, and patent filing requirements on research and development in the EU; 2) assess the appropriate scope and substance of legislative measures and remedies at EU level, and 3) initiate discussions with regard to the prospect and feasibility of adopting harmonised legal instruments on the international level.

I.

As a result of constantly increasing international cooperation in research and development, inventions are more often than before resulting out of collaborations between geographically distributed researchers, research groups, and industry partners. For obvious reasons, this development is supported by the EU. For instance, in Regulation (EU) 1290/2013 on "Horizon 2020" it is noted in Recital 3 that the Framework Programme is intended to

"support the achievement and functioning of the European Research Area in which researchers, scientific knowledge and technology circulate freely, by strengthening cooperation both between the Union and the Member States, and among the

\footnotetext{
${ }^{1}$ Regulation (EU) No 1290/2013 of the European Parliament and of the Council of 11 December 2013 laying down the rules for participation and dissemination in "Horizon 2020 - the Framework Programme for Research and Innovation (2014-2020)" and repealing Regulation(EC) No 1906/2006.
}

Member States, in particular through the application of a coherent set of rules".

It is further recognised that an important object of EU research policies is to ensure efficient dissemination and exploitation of research results. Recital 34 of the Regulation notes that

"in the case of research with the potential for further development into a novel medical technology (such as drugs, vaccines and medical diagnostics), measures should be taken to ensure the immediate exploitation and dissemination of the results, where appropriate".

To this end, Articles 41 to 44 lay down rules on ownership, protection of results, dissemination and exploitation of results, and technology transfer. The effectiveness of these rules is, however, seriously hampered by the fact that neither the Regulation nor other EU legislative measures provide for the harmonisation of national law on inventorship, assignment, and patent filing requirements for multinational inventions. 


\section{II.}

In a legal context, "multinational inventions" can be defined as inventions conceived by two or more inventors of different citizenship and/or residence, and/or inventions assigned to assignees incorporated and/or domiciled in different countries. In all cases involving multinational inventions, questions arise with respect to the choice of law(s) governing inventorship. Choice of law often becomes crucial when national law is not harmonised, as in the present case. Further, as the laws of more than one jurisdiction may apply to the same invention, conflicts of laws may arise. In this regard, ALLEA draws attention to the Association for the Protection of Intellectual Property's (AIPPI) Resolution on Question Q244, adopted on 14 October $2015,{ }^{2}$ noting i.a. that:

"National requirements relating to foreign filings vary significantly from jurisdiction to jurisdiction. In some countries a patent application must be first filed in the country where the invention was made. In some countries, a foreign filing license or procedure for requesting secrecy review prior to foreign filing is available. In other countries, there are no requirements or limitations on foreign filings. Penalties for violation of foreign filing requirements include invalidity of the patent and possible criminal liability."

\section{III.}

To mention only a few illustrative examples of issues arising in the context of the Regulation on "Horizon 2020":

- The general rule that research results shall be owned by the participant generating them (Article 41(1)), presupposes that the national law(s) applicable in each case lay down rules on inventorship and assignment that is compatible with this rule (and with each other, if the laws of two or several jurisdictions apply).

- The rule that the participating parties in certain cases shall have joint ownership to the results (Article $41(2)$ ), is incomplete without harmonised rules governing the dissemination and exploitation of jointly owned inventions.
- The requirement that research results shall be adequately protected "if possible, reasonable and justified given the circumstances” (Article 42(1)), may be impossible to fulfil with respect to multinational inventions. Say, for example, that certain research results are jointly owned by institutions in Poland, Spain, and Italy. In this case, each national law requires the domestic participant to file the first patent application in the member state where it is registered and domiciled. Because the requirements of the national laws concerned are conflicting, they cannot be complied with simultaneously.

IV.

In view of the above findings, ALLEA observes that the lack of harmonisation is apt to cause uncertainties and even legal obstacles which may impede international research collaborations and be detrimental to the efficient dissemination and exploitation of research results.

Therefore, ALLEA invites the European Commission to:

- Analyse the effect of diverging national rules on inventorship, assignment, and patent filing requirements on research and development in the European Union, in particular with respect to inventions resulting from publicly funded research.

- Assess the appropriate scope and substance of legislative measures and remedies on the EU level. Such measures and remedies should, at the very least, lead to the abolishment of presently existing first filing and foreign filing license requirements.

- Initiate discussions with regard to the prospect and feasibility of adopting harmonised legal instruments on the international level.

\footnotetext{
${ }^{2}$ See http://aippi.org/committee/inventorship-of-multinational-inventions/.
} 


\section{ALLEA Permanent Working Group Intellectual Property Rights}

Intellectual Property Rights (IPRs), be it patents or copyrights, play an important role in all academic activities. The ALLEA Permanent Working Group Intellectual Property Rights, which has been in existence since the 1990s, has prepared and issued reflections, declarations and recommendations on the most challenging topics of IPRs. At present it is developing a horizonscanning mechanism to identify emerging issues and suggest appropriate solutions.

\section{About ALLEA (All European Academies)}

ALLEA, the European Federation of Academies of Sciences and Humanities, was founded in 1994 and currently brings together 59 Academies in more than 40 countries from the Council of Europe region. Member Academies operate as learned societies, think tanks and research performing organisations. They are self-governing communities of leaders of scholarly enquiry across all fields of the natural sciences, the social sciences and the humanities. ALLEA therefore provides access to an unparalleled human resource of intellectual excellence, experience and expertise.

February 2018

*ALLEA (All European Academies), Jägerstr. 22/23, 10117 Berlin, Germany; www.allea.org; e-mail: secretariat@allea.org; tel. +49 (0) 30-3259873-72 